Note

\title{
Multiple shoot formation and plant regeneration of a commercially-useful tropical plant, Buchanania lanzan (Spreng)
}

\author{
Sarika Shende, Mahendra Rai* \\ Department of Biotechnology, Amravati University, Amravati-444 602, Maharashtra, India \\ *E-mail: mkrai123@rediffmail.com Tel: +91-721-2662207; Exth 267 Fax: +91-721-2660949
}

Received May 6, 2004; accepted January 13, 2005 (Edited by S. Ogita)

\begin{abstract}
Buchanania lanzan (Spreng) is an endemic but vulnerable plant from the tropical region of India. A tissue culture technique for the rapid clonal multiplication of B. lanzan was developed. The decoated seeds were cultured on MS medium enriched with various concentrations of auxins and cytokinins alone or in combination. Combinations of Benzyl amino purine (BAP) and napthalene acetic acid (NAA) were found to be superior to BAP and Indole butyric acid (IBA). Murashige-Skoog (MS) medium supplemented with $22.2 \mu \mathrm{M}$ of BAP and $5.37 \mu \mathrm{M}$ of NAA promoted formation of the maximum number of shoots. Furthermore, MS medium containing 23.3 $\mu \mathrm{M}$ kinetin induced profuse rooting of the initiated shoots. We propose here that multiple shoot formation is one of the effective techniques for rapid clonal multiplication.
\end{abstract}

Key words: Buchanania lanzan, multiple shoot regeneration, vulnerable tropical plant.

Buchanania lanzan Spreng (Chironji), a member of family Anacardiaceae is a commercially useful tree species throughout the greater part of India. The plant grows on yellow sandy-loam soil. The plant has great medicinal value and the seeds are used as expectorant and tonic. The oil extracted from kernels is applied on skin diseases and also to remove spots and blemishes from the face. The root is used as expectorant, in biliousness and also for curing blood diseases. The juice of the leaves is digestive, expectorant, aphrodisiac and purgative. The gum after mixing with goat milk is used as an analgesic. The tribal people often collect the fruits of this tree to earn their livelihood, through its sale, the tree is consequently overexploited. In the recent past, due to excessive felling of trees and overgrazing, considerable reduction in the population of B. lanzan in the forest and non-forest areas has been recorded (Singh et al. 2002). B. lanzan is included in the Red Data Book published by International Union for Conservation of Nature and Natural Resources (IUCN) as it is a vulnerable medicinal plant.

The seeds are the major source of regeneration of $B$. lanzan in India. The major problem in the reforestation of B. lanzan is the low percentage germination of seeds due to fungal contamination associated with the storage of seeds. Moreover, the fungal attack by Fusarium sp. (wilting disease) is common after sowing the seeds in soil. The seedlings are also attacked by Fusarium monililforme var. subglutinans $\mathrm{Wr}$. and $\mathrm{Rg}$., $F$. semitectum Berk \& Rav. present in soil. Other fungi which occur most frequently include Alternaria alternata (Pr.) Keissler, Aspergillus flavus Link, A. ochraceus
Withelm., A. niger Van Tiegh., A. aculeatus Lizuka, A. funiculosus Smith, Cladosporium Link ex Fr., Chaetomium globosum Kunze and Schm., Curvularia lunata (Wakker) Boedijn, Macrophomina phaseolina Ashby, Mucor varians Povah, Penicillium citrinum Thom., Trichothecium roseum Link., Rhizopus arrhizus and Verticillium species (Sharma et al. 1998). Humidity and high temperature are also conducive to fungal contamination. The seeds exposed to sunlight fail to germinate and soon lose their viability. Another basic problem is the presence of a hard seed coat which leads to low germinating capability. Therefore, in order to ensure further supply of this commercially useful tree species, other breeding methods are required. Plant tissue culture is one of the most useful technologies to micropropagate a plant of interest. We propose a method for multiple shoot formation that is one of the most effective techniques for rapid clonal multiplication. The present research work was undertaken with a view to solve the above problems of severe reduction in numbers of devastation in B. lanzan.

The mature seeds of $B$. lanzan were collected from the forest of Melghat, Amravati District, Maharastra State, India during the year 2002, and were used as a source of explants. The hard seed-coats were removed and they were surface sterilized with $0.5 \%$ mercuric chloride for 15 minutes followed by four washings with sterile distilled water. The whole sterilized seeds with zygotic embryo were placed on MS (Murashige and Skoog) medium (Murashige and Skoog 1962) supplemented with different auxins and cytokinins, adjusted to $\mathrm{pH} 5.8$, and solidified with phytagel $(0.25 \%)$. The chemicals 
Table 1. Effect of BAP, NAA and IBA on multiple shoot formation in B. lanzan.

\begin{tabular}{cc}
\hline Treatment $(\mu \mathrm{M})$ & Number of shoots formed* \\
\hline BAP (17.76)+NAA (5.37) & $1.00 \pm 0.31$ \\
BAP (22.2) +NAA (2.68) & $2.66 \pm 0.84$ \\
BAP (22.2) +NAA (5.37) & $4.00 \pm 1.26$ \\
BAP (26.6) + NAA (5.37) & $3.16 \pm 1.00$ \\
BAP (4.44) + IBA (9.84) & $1.00 \pm 0.33$ \\
BAP (8.88) +IBA (9.84) & $1.24 \pm 0.37$ \\
BAP (13.32)+IBA (9.84) & $1.8 \pm 0.44$ \\
BAP (17.76)+IBA (9.84) & $2.2 \pm 0.49$ \\
BAP (22.2) +IBA (9.84) & $3.0 \pm 0.57$ \\
BAP (26.6) +IBA (9.84) & $2.0 \pm 0.47$ \\
BAP (31.08)+IBA (9.84) & $1.6 \pm 0.42$ \\
BAP (35.52)+IBA (9.84) & $1.1 \pm 0.34$ \\
\hline
\end{tabular}

*All values are means \pm S.D. Mean values are significantly different at $\mathrm{P}<0.05$. Thirty shoots were cultured at each concentration.

used for the experiments were manufactured by $\mathrm{M} / \mathrm{S}$ Himedia company, Mumbai. All the treatments were replicated thrice with 10 culture tubes in each set. The cultures were maintained at $25 \pm 2{ }^{\circ} \mathrm{C}$ with 16 hours illumination at 1500-2000 lux and a relative humidity of $60 \%$. Results were analysed statistically as described by Bailey (1995).

The number of shoots formed per explant and rooting of the shoots were also recorded at regular intervals. It is evident from Table 1 that MS medium when fortified with auxins and cytokinins at different concentrations showed variation in the number of shoots formed. Initiation of shoot formation was noted 10-12 days after inoculations and the maximum of $4.00 \pm 1.26$ shoots were observed on MS medium supplemented with $22.2 \mu \mathrm{M}$ of BAP and $5.37 \mu \mathrm{M}$ of NAA (Figure $1 \mathrm{~A}$ ).

Each of these elongated shoots was independently transferred for rooting in MS medium enriched with varying concentrations of kinetin ranging from 4.64-27.88 $\mu \mathrm{M}$. When the shoots were cut and transferred onto the rooting media, callusing was sometimes observed at the cut base of the shoot before rooting. The rooting was observed after 8-10 days on MS media in kinetin concentration ranging from $4.64 \mu \mathrm{M}$ to $27.9 \mu \mathrm{M}$ (Figure 2), 5-10 roots were formed per shoot. The profuse rooting $(66.7 \%)$ was noted only in kinetin at $23.2 \mu \mathrm{M}, 15$ days after culturing (Figures $1 \mathrm{~B}$ and C).

Singh et al. (2002) reported the maximum rooting per cent at $9.84 \mu \mathrm{M}$ IBA and $11.41 \mu \mathrm{M}$ IAA in non-mist propagation chamber. In our experiment, profuse rooting was obtained in MS medium supplemented with kinetin at $23.2 \mu \mathrm{M}$ concentration at $25 \pm 2^{\circ} \mathrm{C}$ with 16 hours illumination at 1500-2000 lux and a relative humidity of 60\% (Brar and Sandhu 1984; Mathews 1987; Gulati and Jaiwal 1992). Kozai et al. (1992) reported that little research has been conducted on the effect of relative humidity on shoot elongation of in vitro plantlets. It is

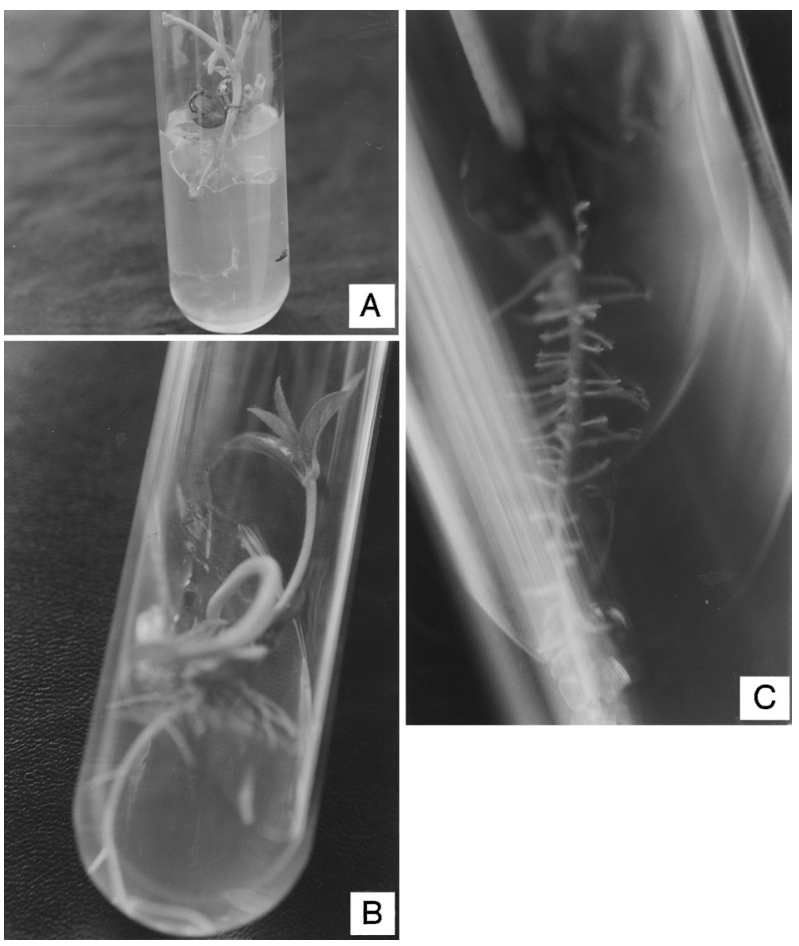

Figure 1. Plant regeneration from seed explant of B. lanzan. (A) Morphology of multiple shoots. (B) A whole plantlet regenerated from an elongated shoot. (C) Magnified view of the main and lateral roots.

well known that a slight reduction in relative humidity in culture vessels increases stomatal functioning, formation of cuticular wax layer, and prevents vitrification of in vitro plantlets. Many investigators have suggested $60-65 \%$ relative humidity for better production of plantlets (Brar and Sandhu 1984; Mathews 1987; Gulati and Jaiwal 1992). Accordingly, in the present investigation, we maintained a relative humidity of $60 \%$.

We conclude that the method described in the present study yielded multiple shoots and root regeneration from the seeds of $B$. lanzan. These results will be very useful in regeneration of this commercially useful but vulnerable medicinal plant.

\section{Aknowledgements}

The authors are thankful to Mr. Gadpande, Forester, Dharni and Dr. A. P. Ramteke, Department of Biotechnology, Amravati University, Amravati for providing seeds for experimental purpose. We are highly thankful to Dr Robin Strang, University of Glasgow, Glasgow G12 8QQ, UK and Professor John Brooker, Microbiology, Avian Sciences Research Centre, SAC Auchincruive, Ayr KA6 5HW, UK, for critically going through the manuscript and for helpful suggestions.

\section{References}

Bailey NTJ (1995) Statistical Methods in Biology. Cambridge University Press, Cambridge. 


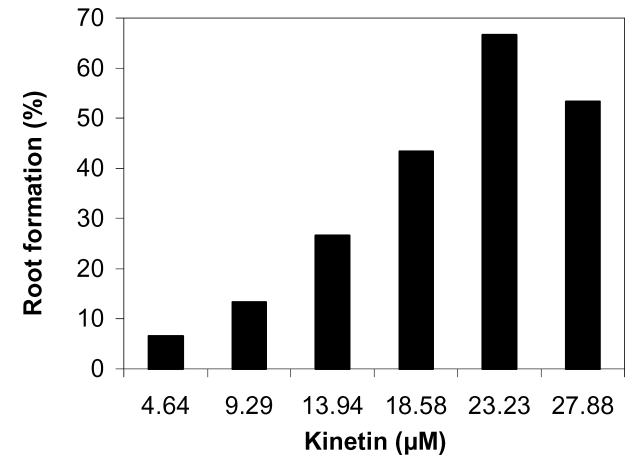

Figure 2. Effect of kinetin on rooting of in vitro grown shoots of $B$. lanzan. Thirty shoots were cultured at indicated concentrations of kinetin. Root formation was estimated by counting regenerated roots among 30 samples and expressed in percentage.

Brar SS, Sandhu BS (1984) In vitro ovule and embryo culture of Gossypium. Curr Sci 53: 1164-1166

Gulati A, Jaiwal PK (1992) In vitro induction of multiple shoots and plant regeneration from shoot tips of mung bean (Vigna radiata (L.) Wilczek). Plant Cell Tiss Org Culture 29: 199_ 205

Kozai T, Tanaka K, Fujiwara K, Watanabe K, Kira S (1992) Effect of relative humidity on the shoot elongation of potato plantlets in vitro. In Abstr Intl Symp Transplant Production Systems, Yokohama, Japan, p 180

Liu C, Shun J, Liu J (1992) In vitro interspecific fertilization, embryo development and formation of hybrid seedlings between Gossypium hirsutum and G. arboreum. Euphytica 60: 79-88

Mathews H (1987) Morphogenetic responses from in vitro cultured seedling explants of mung bean (Vigna radiata L. Wilczek). Plant Cell Tiss Org Culuret 11: 233-240

Murashige T, Skoog M (1962) A revised medium for rapid growth and bioassays with tobacco tissuse culture. Physiol Plant 15: 473-497.

Sharma N, Ghosh R, Nigam M (1998) Toxigenic fungi associated with stored fruits of chironji. Indian Phytopathol 51: 284-286.

Singh J, Patra AK, Nandeshwar DL, Meshram PB, Negi KS (2002) Effect of growth regulators on the rooting of root cuttings of Chironji (Buchanania lanzan Spreng). Proceedings of National Workshop on Conservation of Medicinal Plants. p 128 